\title{
Body composition in HIV-infected patients under combined antiretroviral therapy over $\mathbf{5}$ years
}

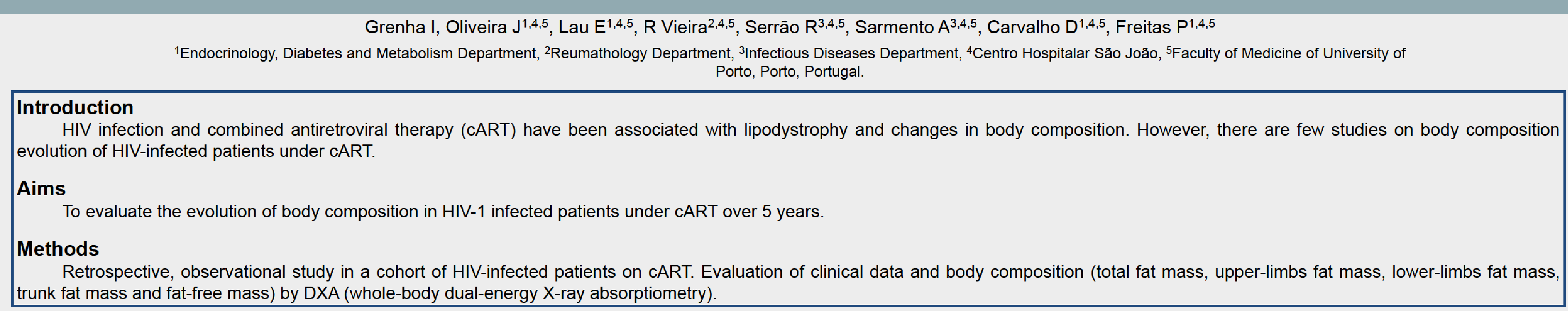

Men | Women
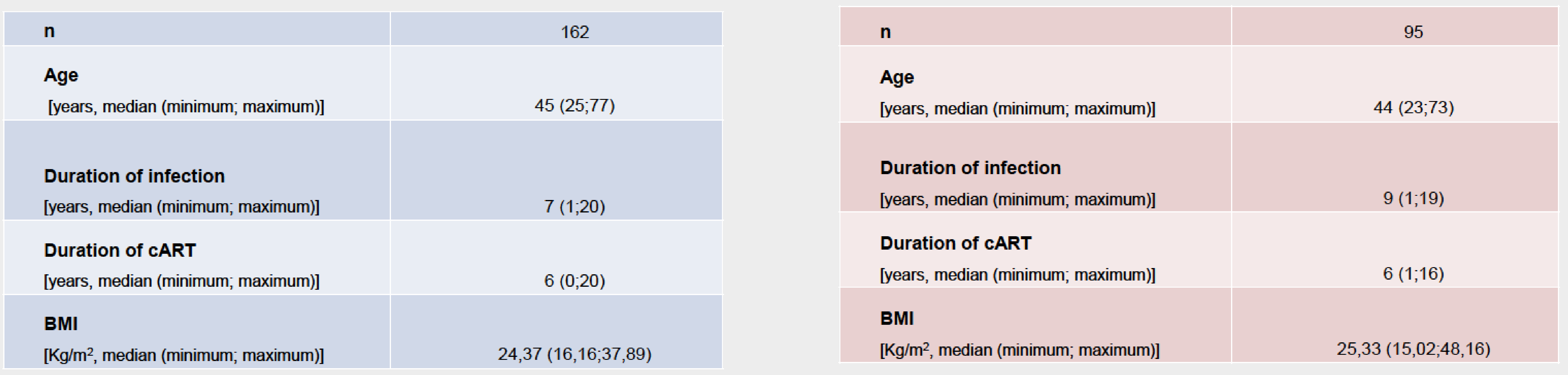

\begin{tabular}{|c|c|c|c|c|c|c|c|c|c|c|c|c|c|}
\hline & $\mathbf{n}$ & Baseline & $\mathbf{n}$ & 1 year after & $\mathbf{n}$ & 2 years after & $\mathbf{n}$ & 3 years after & $\mathbf{n}$ & 4 years after & $\mathbf{n}$ & 5 years after & $p$ \\
\hline $\begin{array}{l}\text { Upper-limbs fat mass } \\
\text { [\%, median (minimum; maximum)] }\end{array}$ & 148 & $14,25(3,7 ; 42,4)$ & 115 & $14,30(3,8 ; 43,6)$ & 98 & $15,15(4,0 ; 46,0)$ & 84 & $15,90(4,3 ; 47,4)$ & 63 & $18,10(5,0 ; 46,0)$ & 47 & $19,60(7,0 ; 45,6)$ & 0,0 \\
\hline $\begin{array}{l}\text { Lower-limbs fat mass } \\
{[\% \text {, median (minimum; maximum)] }}\end{array}$ & 148 & $9,60(3,7 ; 77,0)$ & 115 & $9,80(3,8 ; 38,7)$ & 98 & $10,85(3,7 ; 37,3)$ & 84 & $11,70(3,9 ; 40,9)$ & 63 & $12,10(4,3 ; 37,2)$ & 47 & $13,90(4,6 ; 32,8)$ & 0,0 \\
\hline $\begin{array}{l}\text { Trunk fat mass } \\
{[\% \text {, median (minimum; maximum)] }}\end{array}$ & 148 & $19,90(4,1 ; 44,9)$ & 115 & $21,10(5 ; 50)$ & 98 & $22,60(5,6 ; 51,8)$ & 84 & $23,25(5,3 ; 57,9)$ & 63 & $25,60(6,6 ; 53,0)$ & 47 & $28,90(7,0 ; 46,1)$ & 0,00 \\
\hline $\begin{array}{l}\text { Total fat mass } \\
{[\% \text {, median (minimum; maximum)] }}\end{array}$ & 148 & $15,85(4,0 ; 40,8)$ & 115 & $16,30(4,4 ; 43,5)$ & 98 & $17,45(4,9 ; 44,1)$ & 84 & $18,45(5,0 ; 50,0)$ & 63 & $20,50(6,0 ; 45,0)$ & 47 & $22,10(8,2 ; 40,4)$ & 0,00 \\
\hline $\begin{array}{l}\text { Upper-limbs fat mass } \\
{[g, \text { median (minimum; maximum)] }}\end{array}$ & 148 & $943,00(171 ; 5927)$ & 115 & $1038,00(185 ; 4326)$ & 98 & $1082,50(211 ; 4688)$ & 84 & $1203,50(271 ; 5659)$ & 63 & $1399,00(228 ; 6079)$ & 47 & $1768,00(395 ; 4256)$ & 0,00 \\
\hline $\begin{array}{l}\text { Lower-limbs fat mass } \\
\text { [g, median (minimum; maximum)] }\end{array}$ & 148 & $1943,50(474 ; 10988)$ & 115 & $1905,00(572 ; 12322)$ & 98 & $1991,00(469 ; 13030)$ & 84 & $2162,00(518 ; 14751)$ & 63 & $2661,00(572 ; 12099)$ & 47 & $2762,00(781 ; 10444)$ & \\
\hline $\begin{array}{l}\text { Trunk fat mass } \\
{[g, \text { median (minimum; maximum)] }}\end{array}$ & 148 & 6844,50 (1092;22932) & 115 & $7328,00(1354 ; 27056)$ & 98 & $7791,00(1324 ; 29864)$ & 84 & $8517,00(1386 ; 33294)$ & 63 & $9582,00(1868 ; 29589)$ & 47 & $9961,00(1570 ; 25185)$ & \\
\hline $\begin{array}{l}\text { Total fat mass } \\
{[\mathrm{g} \text {, median (minimum; maximum)] }}\end{array}$ & 148 & $10218,50(2091 ; 41015)$ & 115 & $10930,00(2512 ; 45104)$ & 98 & $11623,50(2213 ; 96610)$ & 84 & $12105,50(1693 ; 54948)$ & 63 & $13954,00(2995 ; 49268)$ & 47 & $16112,00(3979 ; 41086)$ & \\
\hline $\begin{array}{l}\text { Upper-limbs fat-free mass } \\
\text { [g, median (minimum; maximum)] }\end{array}$ & 126 & $5497,50(3734 ; 8597)$ & 102 & $5629,00(3438 ; 52310)$ & 93 & $5735,00(3766 ; 8960)$ & 84 & $5769,50(3459 ; 11129)$ & 62 & $5719,50(3430 ; 9519)$ & 47 & $6409,00(4123 ; 9911)$ & 0,00 \\
\hline $\begin{array}{l}\text { Lower-limbs fat-free mass } \\
\text { [g, median (minimum; maximum)] }\end{array}$ & 126 & $16392,00(11271 ; 21375)$ & 102 & $16461,50(11836 ; 24085)$ & 93 & $15832,00(11267 ; 22702)$ & 84 & $15617,50(11157 ; 20750)$ & 62 & $15947,00(10480 ; 20575)$ & 47 & $16497,00(10799 ; 21081)$ & 0,005 \\
\hline $\begin{array}{l}\text { Trunk fat-free mass } \\
\text { [g, median (minimum; maximum)] }\end{array}$ & 126 & $26916,50(20836 ; 34715)$ & 102 & $26627,00(20232 ; 34760)$ & 93 & 26920,00 (19652;34086) & 84 & $26731,50(19167 ; 33230)$ & 62 & $26270,00(17435 ; 36913)$ & 47 & $24924,00(16771 ; 32950)$ & 0,00 \\
\hline $\begin{array}{l}\text { Total fat-free mass } \\
{[\mathrm{g} \text {, median (minimum; maximum)] }}\end{array}$ & 148 & $53031,50(40978 ; 68000)$ & 115 & $52851,00(41276 ; 71782)$ & 98 & $52200,50(39381 ; 70124)$ & 84 & $51735,00(39790 ; 66773)$ & 63 & $51495,00(38028 ; 68916)$ & 47 & $50666,00(36582 ; 66371)$ & 0,00 \\
\hline
\end{tabular}

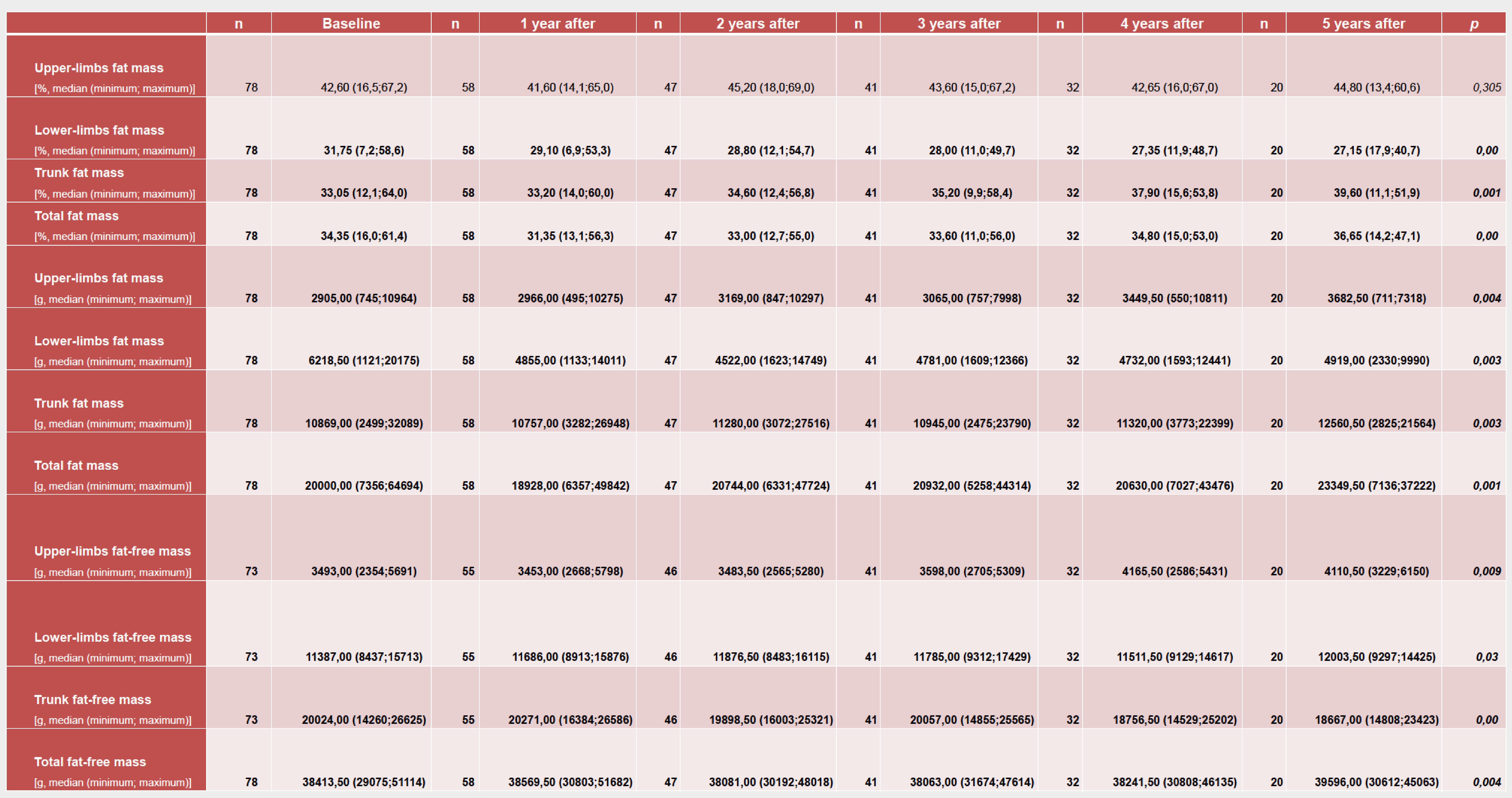

\section{Conclusion}

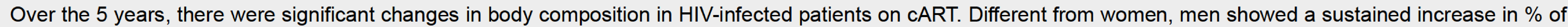
fat mass of all segments evaluated. 